\title{
Una mirada hermenéutica sobre el acto cooperativo ${ }^{1}$
}

\author{
Lenio Luiz Streck \\ Doctor en Derecho del Estado (UFSC/BR) \\ Catedrático de UNISINOS (Brasil)
}

Recibido: $\quad 20.06 .10$

Aceptado: $\quad 8.07 .10$

Sumario: I. La concepción dogmática del acto cooperativo en el Brasil y la necesidad de rompimiento con el paradigma liberal-individualista. 1. Introducción: las sociedades cooperativas, el acto cooperativo y su teorización. 2. Tradición metafísica: vicisitudes y la necesidad del rompimiento. II. La hermenéutica filosófica, sus presupuestos y las bases interpretativas para el acto cooperativo. 1. Lenguaje y comprensión. 2. Fusión de horizontes: lenguaje y paradigma del Estado Democrático de Derecho. III. Presupuestos para la atribución de sentido al acto cooperativo, en el paradigma del Estado Democrático de Derecho. 1. Consideraciones. 2. Estado Democrático de Derecho, Teoría de la Constitución Adecuada y Cooperativismo. 3. Notas conclusivas. Referencias.

Resumen: Las sociedades cooperativas son diferenciadas de las empresariales, pues están muy próximas de los fundamentos del Estado Democrático de Derecho Brasileño. Por eso mismo, el acto cooperativo presenta características particulares, en razón de la finalidad de una sociedad cooperativa: el ejercicio de una actividad económica, de provecho común, sin objetivo de lucro. La conceptuación legal de lo que sea el acto cooperativo es incapaz de contemplar las peculiaridades de las relaciones establecidas en las Sociedades Cooperativas y sus asociados. Así, el sentido de este instituto jurídico debe ser discutido a partir de un nuevo paradigma, marcado por una multiplicidad de demandas por derechos cuya perspectiva ultrapasa la simples apreciación interindividual. Por lo tanto, es necesario que haya una ruptura con las tradicionales «Teorías del Acto Cooperativo», construidas bajo la óptica de un Derecho auto-centrado, de carácter lógico-subsuntivo.

Palabras clave: Sociedades cooperativas; Acto Cooperativo; Teoría del Acto Cooperativo.

Abstract: Cooperative societies are different from entrepreneurial societies, being more connected with the grounds of Brazilian Welfare State. The

1 El artículo fue elaborado en conjunto con el Professor Msc. Mario de Conto, especialista en Derecho Cooperativo (UNISINOS-BR). 
cooperative act presents particular characteristics, because of the purpose of a cooperative society: the exercise of economic activity, with common benefit, without profit intend. The legal concept of cooperative act is unable to contemplate the peculiarities of the relations established in the cooperative societies and their associates. Thus, the meaning of this legal institute must be discussed from a new paradigm, characterized by a multiplicity of demands for rights that surpasses the mere prospect interindividual assessment. Therefore, there must be a break with the traditional «Theories of the Cooperative Act», built from the perspective of a self-centered law, with a logical-subsuntive character.

Key words: Cooperative societies; Cooperative Act; Theory of the Cooperative Act. 


\title{
I. La concepción dogmática del acto cooperativo en el Brasil y la necesidad de rompimiento con el paradigma liberal-individualista
}

\author{
1. Introducción: Las Sociedades Cooperativas, el Acto Cooperativo \\ y su teorización.
}

En Brasil, las Sociedades Cooperativas son regidas por la Ley 5.764/71, que, en su art. 4. ${ }^{\circ}$, las caracteriza como "sociedades de personas, con forma y naturaleza jurídica propias, de naturaleza civil, no sujetas a falencia, constituidas para dar servicios a sus asociados», que enumera sus características intrínsecas².

En ese sentido, las sociedades Cooperativas se presentan como un tipo societarios sui generis, en la medida que su naturaleza jurídica propia las diferencia de las sociedades empresariales. De cierto modo, la consecución de sus finalidades, sintetizada en la ayuda mutua, en la ausencia de fines lucrativos y en la permanente búsqueda de mejorías en las condiciones de vida ${ }^{3}$ de sus asociados están de acuerdo con los fundamentos del Estado Democrático de Derecho, incluidos por la Constitución Federal de 1988, motivo por el cual, los actos practicados por las Sociedades Cooperativas tienen características peculiares.

2 El art. $4 .^{\circ}$ da Ley 5764/71 describe las características das Sociedades Cooperativas, en sus incisos «l. adesão voluntária, com número ilimitado de associados, salvo impossibilidade técnica de prestação de serviços; II. variabilidade do capital social representado por quotas-partes; III. limitação do número de quotas-partes do capital para cada associado, facultado, porém, o estabelecimento de critérios de proporcionalidade, se assim for mais adequado para o cumprimento dos objetivos sociais; IV. inacessibilidade das quotas-partes do capital a terceiros, estranhos à sociedade; V. singularidade de voto, podendo as cooperativas centrais, federações e confederações de cooperativas, com exceção das que exerçam atividade de crédito, optar pelo critério da proporcionalidade; VI. quorum para o funcionamento e deliberação da Assembléia Geral baseado no número de associados e não no capital; VII. retorno das sobras líquidas do exercício, proporcionalmente às operações realizadas pelo associado, salvo deliberação em contrário da Assembléia Geral; VIII. indivisibilidade dos fundos de Reserva e de Assistência Técnica Educacional e Social; IX. neutralidade política e indiscriminação religiosa, racial e social; X. prestação de assistência aos associados, e, quando previsto nos estatutos, aos empregados da cooperativa; XI. área de admissão de associados limitada às possibilidades de reunião, controle, operações e prestação de serviços».

3 En la lección de Waldirio Bulgarelli, «Apresenta-se, assim, o cooperativismo como um sistema reformista da sociedade que quer obter o justo preço, abolindo o intermediário e o assalariado, através da solidariedade e da ajuda mútua. Filosoficamente, o principal objetivo que aspira é o aperfeiçoamento moral do homem, pelo alto sentido ético da solidariedade, complementando na ação, pela melhoria econômica». Bulgarelli, W.: As sociedades cooperativas e sua disciplina jurídica, 2ed., Rio de Janeiro, Renovar, 2000, p. 17. 
Los Actos practicados por las sociedades cooperativas, en ese sentido, presentan características particulares, en razón de que sus finalidades son diferentes $-\mathrm{y}$, muchas veces antagónicas - de las demás sociedades empresariales. En la realización de sus objetivos, las sociedades cooperativas practican el denominado "Acto Cooperativo», cuyo sentido y alcance se ha evidenciado como punto de conflicto interpretativo, trayendo repercusiones serias al sistema cooperativista nacional.

El Acto Cooperativo es disciplinado en el art. 79 de la Ley 5.764/71que informa que

Denominam-se atos cooperativos os praticados entre as cooperativas e seus associados, entre estes e aquelas e pelas cooperativas entre si quando associados, para a consecução dos objetivos sociais. Parágrafo único. O ato cooperativo não implica operação de mercado, nem contrato de compra e venda de produto ou mercadoria.

Además, de la interpretación de lo dispuesto en el art. $3 .^{\circ 4}$ de la ley aludida, resta evidente que el Acto Cooperativo se relaciona al «ejercicios de una actividad económica, de provecho común, sin objetivo de lucro».

La conceptuación legal, por una impropiedad natural, es incapaz de contemplar las peculiaridades de las relaciones establecidas en las Sociedades Cooperativas y sus asociados. Así, el alcance del dispositivo solo puede ser establecido, de forma adecuada, por un paradigma interpretativo que considere la complejidad de las relaciones por el regladas y que se de cuenta del paradigma establecido en la Constitución de 1988, al cual todo el ordenamiento jurídico se encuentra sometido. En verdad, se trata de discutir el sentido del fenómeno «Acto Cooperativo» como instituto jurídico inserido en una sociedad con una multiplicidad de demandas por derechos cuya perspectiva ultrapasa la simples apreciación interindividual. Ese parece ser el principal punto del problema: comprender el "acto cooperativo» a partir de un nuevo paradigma establecido por el Estado Democrático de Derecho.

Todavía, lo que se percibe es la utilización de las llamadas «Teorías del Acto Cooperativo», construidas bajo la óptica de un Derecho autocentrado, de carácter lógico-subsuntivo, ligado a la idea de que, a partir del concepto legal, sería posible, por medio del método deductivo, verificar cual situación se adecúa o no al concepto legal electo como

4 Art. $3 .^{\circ}$ Celebram contrato de sociedade cooperativa as pessoas que reciprocamente se obrigam a contribuir com bens ou serviços para o exercício de uma atividade econômica, de proveito comum, sem objetivo de lucro. 
categoría de precepto primordial-fundante. Ese, alias, es el talón de Aquiles de la teoría del derecho y del positivismo jurídico: pretender la construcción de conceptos que abarquen de antemano todas las hipótesis de aplicación, como si fuera posible cumplir la compleja realidad en el interior de un concepto jurídico.

Básicamente, para la Teoría Pura del Acto Cooperativo, este estaría configurado, restrictivamente, solamente en las hipótesis descriptas en el art. 79 de la Ley 5.764/71. Dicho de otro modo: por tal teoría, solamente serían "Actos Cooperativos», los denominados actos internos, realizados entre cooperativas y asociados y entre cooperativas, desde que asociadas entre sí. De esa forma, para la Teoría Pura del Acto Cooperativo, los actos realizados con terceros se caracterizarían como actos mercantiles.

Ya para la denominada Teoría Mixta del Acto Cooperativo, además de los actos internos, podrían ser entendidos como actos Cooperativos aquellos practicados por la sociedad cooperativa para la ejecución de sus objetivos sociales. En ese sentido, se ampliarían las posibilidades, en la medida que en las operaciones con terceros, realizadas en cumplimiento a los objetivos estatutarios de las sociedades cooperativas, se configurarían como Actos Cooperativos y no como actos mercantiles.

Las dos teorías, evidentemente, presentan restricciones. Si es verdad que la «Teoría Mixta» presenta ambigüedades, en especial, la dificultad de distinción entre acto cooperativo y acto de mercado, la «Teoría pura» presenta una interpretación restrictiva que no se adecua a la finalidad de la sociedad cooperativa en los tiempos cotidianos.

Es en ese sentido que la nueva generación enfrenta un desafío inexistente para los clásicos (o tradicionales). A lo largo de las tres últimas décadas, el cooperativismo brasilero se diversificó, con el surgimiento de nuevos ramos, así como las operaciones de las cooperativas se hicieron más complejas, con la agregación por la cooperativa de valor a la actividad económica realizada por el cooperado. Así, el acto cooperativo se consubstanció en diversas expresiones plurimas 5 .

5 [1] La Ley 5.764/71, como se sabe, tubo por paradigma, las operaciones realizadas por las cooperativas rurales. Grande parte de las dificultades hoy encontradas en la interpretación da Ley pude ser solucionada, con una redacción con expresiones más generales, que contemplen cooperativas dos diversos ramos. Especial atención merece el examen del nexo, por cuenta de la actual jurisprudencia, que exige identidad de objeto, para reconocer nexo entre el acto de mercado, como negocio de medio, y el acto cooperativo, negocio-fin. Paradigmática es el siguiente precedente:

TRIBUTÁRIO-ISS-COOPERATIVA MÉDICA-ATO COOPERADO-ISENÇÃO: 1. As cooperativas podem praticar atos cooperados, ao coordenar e planejar o trabalho 
La complejidad de las relaciones establecidas entre las Sociedades Cooperativas y sus asociados, así como la superveniencia de un modelo constitucional en que el cooperativismo recibió status de modelo económico a ser apoyado y estimulado, torno anacrónicas las teorías del Acto Cooperativo, las cuales fueron elaboradas principalmente a partir de una visión vinculada al Cooperativismo Agropecuario.

\section{Tradición metafísica: vicisitudes y la necesidad del rompimiento}

Las deficiencias del modo clasificatorio entre «Teoría pura»y «Teoría mixta» del acto Cooperativo, demuestran, antes de todo, las insuficiencias de un modo de pensar fundado en el paradigma liberal-individualista, de carácter metafísico.

de seus associados, os quais recebem pelo trabalho realizado, com isenção de tributos, nos termos da Lei 5.764/71, artigo 79. 2. Diferentemente, podem as cooperativas na captação de clientes firmarem com estes ato negocial, vendendo planos de saúde, recebendo dos terceiros importância pelo serviço realizado, sem isenção alguma porque de ato cooperado não se trata. 3. Hipótese dos autos em que a cooperativa age intermediando os serviços de seus próprios associados, os médicos, reunidos em prol de um trabalho comum, exercendo verdadeiro ato cooperativo. 4. Recurso especial improvido. (REsp 487854 / SP-Rel. Min,. ELIANA CALMON-DJ 23.08.2004).

El método del pensamiento que construye tal conclusión pasa por la percepción que, si el objeto del acto cooperativo en una cooperativa de prestadores de servicios profesionales es el trabajo de los socios, si ese es el objeto del contracto de la cooperativa celebrado en el mercado, entonces es reconocida la práctica de un negocio-medio. Todavía, en el caso de una operadora de planes de salud, el objeto del contracto celebrado en el mercado es esa operación, y no el servicio médico del socio. Esa variable ha sido suficiente para que o STJ invierta toda la lógica que construyó para un adecuado tratamiento tributario al acto cooperativo.

De hecho, el método no es equivocado del todo, pues, con él, el STJ logró percibir que las cooperativas de crédito no podrían someterse a la Súmula 262, como ya indica en los precedentes sobre la no incidencia de la contribución del PIS y de la COFINS en los ingresos originados de la aplicación financiera realizada con recursos de los socios. Todavía, es importante reconocer que las cooperativas hoy, en grande medida, justifican su existencia, cuando agregan valor a la actividad económica de los socios. Y, en esa agregación, pueden alterar la esencia del objeto del acto cooperativo, cuando operan en el mercado. Eso ocurre en la industrialización de productos agropecuarios. No se imagina hoy un cooperativismo agropecuario actuante sin sus plantas industriales, sin una total inserción competitiva en el agronegocio. Fenómeno semejante ocurre en las cooperativas médicas e odontológicas. La diferencia está más en la materialidad de los objetos de los respectivos actos cooperativos y de los negocios-medio. Y eso no da, d.m.v., razón a un tratamiento tan radicalmente distinto sobre la incidencia tributaria en cada caso, como se verifica actualmente en la jurisprudencia. 
Para el modo de pensar metafísico-representacional, la comprensión, por medio de la elaboración de conceptos, estaba vinculada a los fundamentos últimos y a la clasificación de «categorías«. Para la teoría tradicional del derecho (teorías positivistas lato sensu) la comprensión y el conocimiento están vinculados a la idea de la inducción, por la cual se formulan conceptos. Los enunciados expresan las verdades, que detienen un carácter absoluto y universal. Russel constató el carácter negativo de la diseminación de la filosofía aristotélica, al aseverar que, «historicamente, a influência de Aristóteles tem sido muito obstrutiva, principalmente devido ao dogmatismo cego servil de muitos dos seus seguidores. Naturalmente, não podemos censurar Aristóteles por isso» ${ }^{6}$.

Después de pasar por la Antigüedad y la Edad Media, el modo de pensar metafísico encontró su auge en la modernidad iluminista, a pesar de la inversión de perspectiva, pues la idea de subjetividad es efectivamente un producto del modo de "pensar moderno». De todo modo, con la pretensión de separar las indeterminaciones que caracterizaron el medievo, el modo de pensar metafísico viene, por medio de objetificaciones, presentar la solución de seguridad de que necesitaba la burguesía para fortalecer la todavía incipiente economía. La dogmática jurídica, entendida como producto de la modernidad, fue construida totalmente en tal perspectiva. Se parte del presupuesto de que la verdad de la ley está encarcelada en su enunciado lingüístico y que al intérprete le toca, por medio de la utilización de métodos-formales y subsuntivos aplicar la verdad contenida en el enunciado al caso concreto. Si la modernidad se instaura a partir de la idea de contracto, es en la voluntad general (ley) que esa institucionalización ocurre. Pero, para tanto, tenía que conceder en favor del sujeto solipsista (del esquema sujeto-objeto) y de la discrecionalidad (principal característica del positivismo) las insuficiencias de la razón teórica.

En las primeras décadas del siglo xx ocurre una verdadera revolución copernicana en esa forma de pensar. Si en la metafísica clásica el sentido estaba en las «cosas», porque estas tenían una esencia, en la metafísica moderna los sentidos pasaron a ser propiedad del sujeto que se instauró a partir del cogito (racionalidad). Heidegger y Wittgenstein pueden ser considerados los corifeos de un cambio lingüístico-ontológico, introduciendo el mundo practico en la filosofía. Si la filosofía es hermenéutica (ultrapasando la epistemología), la hermenéutica pasó a

6 Russel, B.: História do Pensamento Ocidental, Rio de Janeiro, Ediouro, 2004, p. 125. 
ser entendida después de Gadamer, como productora de sentidos (hermenéutica filosófica). Interpretar la ley pasó a ser aplicación.

Se trataba de ultrapasar, fundamentalmente, el pensamiento objetificador y representacional. Si el pensamiento objetificador del derecho buscaba la construcción de una razón teórica con pretensiones autónomas, el sentido del derecho acababa siendo dislocado para la multiplicidad de sentidos abstractos, como si fuera posible al derecho prevenir - como ya fue dicho- las innúmeras posibilidades de inserción de la norma en la realidad social. En el fondo -y ese es un problema aún corriente en el campo de la dogmática jurídica- el jurista trabaja con «conceptos sin cosas». Esta quizá sea la principal razón por la cual una compleja realidad que envuelve el acto cooperativo no puede ser «absorbida» por el paradigma del derecho aún sustentado en la vieja figura del «sujeto-individualista-propietario-de-mercancías».

Dicho de otro modo: el sentido del ser del ente "Acto cooperativo» no puede ser visto, únicamente, bajo la óptica de teorías «entificantes» que lo limitan. La atribución de sentido al acto cooperativo, pasa, indubitablemente, por la denuncia del conocimiento entificador y por la búsqueda de un sentido adecuado, en el paradigma del Estado Democrático de Derecho. Una ducha de facticidad puede ser un modo de traer la discusión del "acto cooperativo» para el seno de la complejidad social.

Así, a partir de la matriz teórica de la hermenéutica filosófica, la comprensión deja de ter un aspecto metodológico. Es lo que se puede llamar, a partir de la filosofía hermenéutica y de la hermenéutica filosófica, de un "paso de regreso ${ }^{7} »$, pero, que, al mismo tiempo, es un «paso superador», para más allá del «paraíso de los conceptos» de la tradición jurídica, así como para más allá de las concepciones céticas,

7 «Passo de volta não quer dizer um passo isolado do pensamento, mas o tipo de movimento do pensamento e um longo caminho. Na medida em que o passo de volta determina o caráter de nosso diálogo com a história do pensamento ocidental, o pensamento conduz de certo modo para fora do que até agora foi pensado em filosofia. $\mathrm{O}$ pensamento recua diante do seu objeto, o Ser, e põe o que foi assim pensado num confronto, em que vemos o todo desta história, e em verdade sob o ponto de vista daquilo que constitui a fonte de todo este pensamento, enquanto Ihe prepara um fim a esfera de sua residência (...). Falamos da Diferença entre o Ser e o ente. O passo de volta vai do impensado, da diferença enquanto tal, para dentro do que deve ser pensado. Isto é esquecimento da Diferença. O esquecimento a ser aqui pensado é o velamento da Diferença enquanto tal, pensado a partir do LETHE (ocultamento), velamento que por seu lado originariamente se subtrai. O esquecimento pertence à Diferença, porque esta pertence àquele. $\mathrm{O}$ esquecimento não surpreende a Diferença apenas posteriormente, em conseqüência de uma distração do pensamento humano». Heidegger, M.: A Constituição onto-teo-lógica da metafísica, Pfullingen, Gunther Neske, 1957, tradução de Ernildo Stein, p. 10. ISSN: 1134 - 993X, Núm. 44/2010, Bilbao, págs. 111-129 
para las cuales el texto jurídico nada vale o poco vale (circunstancias que fragiliza la noción de Constitución normativa, fundamental para la democracia sustentada en él y para el Derecho).

De esa forma, el «paso de regreso» se caracteriza por la busca del sentido de la "Cooperación», por la denuncia de la insuficiencia de las Teorías Pura y Mixta para la comprensión del fenómeno del acto cooperativo y, así, superar las dicotomías y atribuir sentido adecuado al acto cooperativo en el paradigma del Estado Democrático de Derecho.

\section{La hermenéutica filosófica, sus presupuestos y las bases interpretativas para el acto cooperativo}

\section{Lenguaje y comprensión}

«El lenguaje habla». Es a partir de la asertiva que Heidegger presenta el carácter paradigmático del lenguaje. No se trata, obviamente, de una comprensión objetiva del lenguaje, pero de la percepción de que el lenguaje es condición de posibilidad para que las cosas estén en el mundo 8 .

Para Heidegger, el ser es comprehendido en el lenguaje. Así, el lenguaje (que surge en la falta y en la expresión del ser-con) pasa a ser condición de posibilidad para que las cosas estén en el mundo. Con la atribución del sentido se da la transcendencia y en la intersubjetividad, la relación metafísica sujeto-objeto es superada por la concepción hermenéutica de que el sentido es atribuido por medio de una relación sujeto-sujeto, con el lenguaje ejerciendo el papel central.

Un ejemplo de eso es la noción de «lucha de clases», elaborada por Marx. Evidentemente, Marx no crio la lucha de clases, propiamente dicha. La «lucha de clases siempre estuvo presente, en la tensa relación entre capital y trabajo. Todavía, una vez que Marx denomino el fenómeno, el mismo pasó a ser parte del mundo. A partir de entonces, tenemos como «lucha de clases» y «plus-valía», viene siendo empleada en las más diversas teorías, siendo re-elaboradas y re-presentadas por medio de la tradición.

Hegel, de igual manera, no fue el inventor de la dialéctica. Las tesis, antítesis y síntesis siempre existieron y siempre existirán, es que hacen parte del proceso de conocimiento humano. Todavía, la «dialéctica he-

8 Heidegger percibe el «abismo gnoseológico» que se establece entre el hombre y las cosas. Entiende, de esa manera, que el lenguaje es condición de posibilidad para que las cosas estén en el mundo. 
geliana», nombre atribuido al fenómeno por el filosofo, siempre remeterá a tal fenómeno, en la medida en que el pasó a ser conocido en el mundo a partir del momento en que fue nombrado.

Otros fenómenos, todavía, solamente la distancia temporal (utilizándose los enseñamientos de Gadamer) son capaces de nombrar. En ese sentido, en la contemporaneidad podemos, al ver el pasado de la humanidad, caracterizar momentos históricos y nombrarlos como «Edad Media», «Edad Moderna» y atribuirles características intrínsecas. De esa forma, el Lenguaje, sumado al fenómeno de la «Distancia Temporal» igualmente posee papel criador 9 .

En lo que dice respeto a las Sociedades Cooperativas, se percibe fenómeno análogo. Se puede considerar que el hombre, desde los primordios, entienda que por medio de la ayuda mutua puede obtener mejores resultados. No hay duda de que, anteriormente a 1844 (año en que oficialmente surgió la primera cooperativa) hayan existido otras formas de organización basadas en el trabajo solidario y en la división de sus resultados.

De esa forma, si ya existían otras formas de asociación anteriormente a Rochdale, cual sería, en síntesis, el diferencial de tal iniciativa? El diferencial que dice respeto a la nominación de una experiencia sui generis. El diferencial que surge de la atribución de la palabra «cooperativa» a una nueva forma de organización social, fundamentada en principios de ayuda mutua, destinado a la obtención de mejores condiciones económicas. De ahí que

Um dos principais legados de Rochdale, talvez, foi o de criar uma entidade que, visando solucionar problemas econômicos, tentou superar o tipo de entidades então existentes na área econômico-produtiva: criam uma empresa ao mesmo tempo respeitadora das pessoas (sociedade de pessoas, democrática, com primazia do trabalho sobre o capital) e que se orienta à crescente melhoria na prestação dos serviços para os seus reais donos e usuários, inspirada na auto-ajuda comunitária. Por ser uma empresa e, portanto, diretamente comprometida com o processo produtivo, devia também ser racional e eficiente ${ }^{10}$.

9 Como observa Grondin: «Nossos esboços, de início, não são de nossa escolha. Somos, antes, «jogados» neles. O específico «ser lançado» e a historicidade do ser-aí são a característica indelével de nossa «facticidade». Faz parte da pré-estrutura fática e,com isso, primária do nosso compreender, as que ela se encontre no âmbito das perspectivas prévias, que orientam suas expectativas de sentido». Grondin, J.: Introdução à Hermenêutica Filosófica, São Leopoldo, Editora Unisinos, 2004, p. 163.

10 Schneider, O.: Democracia, participação e autonomia cooperativa, São Leopoldo, Editora Unisinos, p. 35. 
En resumen, es a partir de la superación de la relación sujeto-objeto por la relación sujeto-sujeto, que el lenguaje pasa a desarrollar papel fundamental en el proceso de comprensión, es que por medio de él, es que se toma contacto con el mundo de la vida, en el cual él interprete es inserido. Por eso es posible hablar, hoy, en la existencia de una razón hermenéutica, caracterizada por la relevante circunstancia de que la precomprensión es estructurante. O sea, la relación del hombre con el lenguaje se caracteriza por la noción de co-pertenencia: el lenguaje pertenece al hombre, así como el hombre al lenguaje. Es en ese sentido que surge la preocupación con la cuestión del lenguaje, como la constructora del mundo, de valores y de tradiciones. Por lo tanto, es por medio del lenguaje que el intérprete toma contacto con las tradiciones, lo que hace con que el lenguaje -anteriormente considerada un simple vehículo de conceptos- pasa a ser condición de posibilidad para la comprensión ${ }^{11}$.

En resumen, es por medio del lenguaje y dela intersubjetividad que el interprete tiene acceso a los valores, a los prejuicios que harán parte de su comprensión. Es a partir de ella que se manifiesta la transcendencia del Dasein, a partir de la cual surgirá la atribución de sentido. Todavía, el problema que surge de tal constatación y que será objeto de análisis a seguir, se refiere a la autenticidad de tales juicios previos.

\section{Fusión de Horizontes: Lenguaje y Paradigma del Estado Democrático de Derecho}

Gadamer presenta la noción de dialogo con la tradición como condición de posibilidad de verificación de los prejuicios. Para el filósofo, el intérprete, al tomar contacto con la tradición, no se debe aceptarla pasivamente ${ }^{12}$. Es en ese espirito que Gadamer asevera que:

11 En ese sentido, Gadamer explica que «a compreensão implica sempre uma précompreensão que, por sua vez, é prefigurada por uma tradição determinada em que vive o intérprete e que modela os seus pré-conceitos. Assim, todo encontro significa suspensão de meus preconceitos, seja o encontro com uma pessoa com quem aprendo a minha natureza e os meus limites, seja com uma obra de arte («não há um lugar em que não possa ver-te, deves mudar a tua vida») ou com um texto; e é impossível contentar-se em "compreender o outro», quer dizer, buscar e reconhecer a coerência imanente aos significados-exigências do outro». Gadamer, H.: O problema da consciência histórica. Rio de Janeiro, Editora Fundação Getúlio Vargas, 1998, pp. 13-14.

12 Rui Sampaio da Silva establece relación entre el Dasein y términos Gadamerianos como «trabajo de la historia.» y de «consciencia del trabajo de la historia». Expone que «a primeira noção designa nossa pertença à história, a superioridade da história sobre a consciência humana e o fato de a nossa abertura ao mundo ser determinada previamente pela tradição em que nos movemos. A noção correspondente de «consciência do 
a consciência moderna assume — precisamente como "consciência histórica»—- uma posição reflexiva com relação a tudo que lhe é transmitido pela tradição. A consciência histórica já não escuta beatificamente a voz que lhe chega do passado, mas, ao refletir sobre ela mesma, recoloca-a no contexto em que ela se originou, a fim de ver o significado e o valor relativos que lhe são próprios. Esse comportamento reflexivo diante da tradição chama-se interpretação. ${ }^{13}$

Como resto explicitado, punto crucial para la fenomenología hermenéutica (que puede ser traducida por la junción de los aportes de la filosofía hermenéutica y de la hermenéutica filosófica) es ruptura con la postura objetificadora de la metafísica ${ }^{14}$. Aquí asume especial relevancia la noción del círculo hermenéutico y de la fusión de horizontes. Es en ese contexto que se evidencia el carácter productivo de la comprensión. En la interpretación, la busca por el desvelar de los sentidos es un proceso ontológico (en el sentido de la ontología fundamental) y no se da por procedimientos lógico-formales. En ese contexto, tradición y la libertad son elementos esenciales en la construcción de los sentidos. No hay grado de cero de sentido y tampoco aprisionamiento al pasado. En el decir de Vattimo, "o abrir-se ao ente não é algo que o homem possa escolher porque constitui o próprio Dasein como tal enquanto «ser-nomundo». Esta liberdade não é, pois, uma faculdade de que o homem disponha, mas é ela que dispõe o homem». ${ }^{15}$

trabalho da história» deve ser lida no duplo sentido do genitivo: significa, por um lado, a consciência que temos do trabalho da história e, por outro, a consciência que é dominada ou possuída pela história. Como se vê, são claras as afinidades com a noção de Dasein. As duas noções denunciam a inadequação da concepção tradicional do sujeito e da consciência, chamando a atenção para a pertença necessária do homem a um contexto histórico e social, bem como para o facto de o homem ser «mais ser do que consciência», como exprime Gadamer. A Consciência do trabalho da história assemelha-se muito ao Dasein, desde que esteja depurado dos traços transcendentais que possuía sem Ser e Tempo». Silva, R.S. da: "Gadamer e a herança Heideggeriana», Revista Portuguesa de Filosofia, 56, 2000, p. 524.

13 Gadamer, H.: O problema da consciência histórica, Rio de Janeiro, Editora Fundação Getúlio Vargas, 1998, pp. 18-19.

14 Pires informa que «toda a metafísica ocidental, desde Platão e Aristóteles que determinaram os conceitos filosóficos do Ocidente e abriram os caminhos da civilização européia, até Hegel e Nietzsche em que essa metafísica começa a chegar à sua consumação, vive do esquecimento do ser (Seinsvergessenheit). A metafísica tradicional pensou o ente enquanto tal, mas esqueceu do ser dos entes. É verdade que ela dalgum modo pensa o ser dos entes, mas só enquanto reflete sobre os entes. O ser mesmo (das Sein selbst) foge ao olhar da metafísica.» Pires, C.: «Heidegger e o ser como história». Revista Portuguesa de Filosofia, Braga, tomo XIX julho-setembro 1963, Fasc. 3.

15 Vattimo, G.: Introdução à Heidegger, Lisboa, Edições 70, 1977, p. 74. 
Las tesis hermenéuticas (en especial las provenientes de Gadamer) han sido fecundas para la formulación del(os) método(s) concretista(s) de la interpretación del Derecho. En ese sentido, Konrad Hesse, partiendo de Gadamer, propone nuevos horizontes para la hermenéutica jurídica. Para Hesse, el contenido de la norma (texto) solamente se complementa en el acto interpretativo. La concretización de la norma por el intérprete va presuponer (siempre) una comprensión de esta; esa comprensión presupone una precomprensión. Así, partiendo de Gadamer, Hesse ${ }^{16}$ muestra como el momento de la pre-comprensión determina el proceso de concretización: la concretización presupone la comprensión de contenido del texto jurídico a concretizar, la cual no se debe desvincular ni de la precomprensión del intérprete ni del problema concreto a solucionar. El intérprete no puede captar el contenido de la norma desde el punto de vista casi arquimédico asentado fuera de la existencia histórica, sino únicamente desde la concreta situación histórica en la cual se encuentra, cuya elaboración (maturidad) conformó sus hábitos mentales, condicionando sus conocimientos y sus prejuicios. Él interprete comprende el contenido de la norma a partir de una precomprensión, que es lo que le va permitir contemplar la norma desde ciertas expectativas, hacer una idea del conjunto y perfilar un primero proyecto, aun necesitado de comprobación, corrección y revisión por medio de progresiva aproximación a la cosa por parte de los proyectos en cada caso revisados con lo que la unidad de sentido queda claramente fijada. Dada esta presencia del prejuicio en toda comprensión, se trata de no limitarse a ejecutar las anticipaciones de precomprensión, sino de, por lo contrario, consciente de las mismas y explicándolas, respondiendo así al primer comando de toda interpretación: protegerse contra el arbitrio de las ideas y las estrechez de los hábitos de pensar imperceptibles y direccionar la mirada «para las cosas mismas». Así la tarea puesta para la fundamentación de la precomprensión es, sobremodo, una tarea de la teoría constitucional que, por su vez, no es discrecional si ella es obtenida con vista a la orden constitucional concreta $y$, en continuo dar y tomar, confirmada y corregida por la práctica del caso concreto, aduce el maestro alemán.

De esa forma, resta evidente que los presupuestos de la hermenéutica filosófica deben servir con instrumentos del desvelar del sentido del «Acto Cooperativo», practicados por las Sociedades Cooperativas, en el paradigma del Estado Democrático de Derecho. Hermenéutica es «atri-

16 Cfe. Hesse, K.: Escritos de derecho constitucional. 2. ed., Madrid, Centro Estud. Constitucionales, 1992, e ___ : Elementos de direito constitucional da República Federal da Alemanha. Porto Alegre: Sergio Antonio Fabris, 1998, p. 62. 
bución de sentido», tarea que se desenlaza a partir de la facticidad y de historicidad del intérprete, Es por eso que sustentamos que una adecuada interpretación del "acto cooperativo» debe ser hecha llevando en cuenta el nuevo paradigma intersubjetivo que se desarrolla a partir del segundo pos-guerra, a partir de lo que se convencionó llamar de "girolingüístico-ontológico». Y, en ese sentido, no tenemos duda de que el derecho no puede quedar inmune a las influencias de ese nuevo paradigma.

\section{Presupuestos para la atribución de sentido al acto cooperativo, en el paradigma del Estado Democrático de Derecho}

\section{Consideraciones}

A partir de los presupuestos lanzados, se llega al momento de su aplicación, considerándose:

I. Que el lenguaje posee función formadora del mundo y de una noción de "Acto cooperativo» que debe estar relacionada a las características intrínsecas de las sociedades Cooperativas.

II. La comprensión de fusión de horizontes, entre los legados de la tradición relacionado al Acto Cooperativo y la adecuación de tales legados a los paradigmas del Estado Democrático de Derecho.

II. El necesario rompimiento con el «modo de pensar metafísico» (conceptualistas), demostrado a partir de la dogmatica Jurídica de carácter liberal-individualista, buscando superar las dicotomías teóricas anacrónicas que cercan el Acto Cooperativo.

IV. Por medio de la concepción ambivalente de verdad, manifestada por la Hermenéutica Filosófica, atribuir sentido adecuado al Acto Cooperativo, al considerar las características de las sociedades cooperativas, los principios doctrinarios que las dirigen y la correspondencia con los valores tutelados por el paradigma del Estado Democrático de Derecho.

2. Estado Democrático de Derecho, Teoría de la constitución Adecuada y Cooperativismo

Canotilho, al hablar sobre la Constitución, informa que no hay una teoría de la constitución dominante, pero las teorías adecuadas a de- 
terminados modelos constitucionales. El enseñamiento de Canotilho, en ese sentido, es que, en no habiendo una teoría absoluta, se debe comprender que «una Teoría de la Constitución, si quiere ser de alguna utilidad para la metodología del derecho constitucional, se debe revelar como una teoría de la constitución constitucionalmente adecuada» ${ }^{17}$. Es en ese sentido que se impone el análisis de las vicisitudes del modelo constitucional brasilero, en busca de la construcción de una Teoría de la Constitución adecuada, llevando en consideración la importancia atribuida al Cooperativismo en el paradigma del Estado Democrático de Derecho.

Al abordar los «topoi» categoriales de una teoría de la constitución, Canotilho enfatiza la «historicidad de la constitución», afirmando que «uno de los temas centrales de la teoría de constitución es su «localización temporal», su «entrada en el tiempo», su «abertura al tiempo», $\mathrm{su}$ «historicidad» 18

De esa forma, un necesario análisis histórico del modelo constitucional brasilero, revela un constitucionalismo sujeto a sucesivos avanzos y retrocesos, notablemente después de la (re)democratización del país que en 1985, cerró las cortinas de la hipocresía relacionada a la efectivación de Derechos Sociales.

En ese sentido, la Constitución de 1988, considerada en su horizonte histórico, nasce como una aspiración de la sociedad a la realización de los Derechos Fundamentales Sociales, como un instrumento compromisario, destinado a la transformación de la realidad social.

Inserida en ese contexto, el análisis del preámbulo de la Constitución Federal demuestra la carga histórica presente en el instrumento, que materializó la liberación de un régimen dictatorial, y la promesa de institución de un Estado Democrático, «destinado a asegurar el ejercicio de los derechos sociales e individuales a la libertada, a la seguridad, al bien-estar, al desarrollo, a la igualdad y a la justicia como valores supremos de una sociedad fraterna, pluralista y sin preconceptos fundad en la harmonía social y comprometida, en el orden interno e internacional, con la solución pacífica de las controversias».

Partiendo, en ese sentido, del análisis de algunos fragmentos del texto constitucional se percibe que la Constitución de la república determina, en su art. $1 .^{\circ}$ que "A República Federativa do Brasil, formada pela União indissolúvel dos Estados e Municípios e do Distrito Federal,

17 Canotilho, J.J.G.: Constituição Dirigente e Vinculação do Legislador: Contributo para a compreensão das normas constitucionais programáticas, Coimbra, Coimbra editora Ltda, 1994, p. 79.

18 Idem, ibidem, p. 131. 
constitui-se em Estado Democrático de Direito e tem como fundamentos: I. A soberania; II. a cidadania; III. a dignidade da pessoa humana; IV. os valores sociais do trabalho e da livre iniciativa; V. o pluralismo político».

Resta evidente que los fundamentos del Estado Democrático de Derecho, en ese sentido, están centralizados en el ejercicio de la ciudadanía que se consubstancia en la atribución de libertades y en la tutela de la dignidad de la persona humana. Además, el art. 3. informa que «constituem objetivos fundamentais da República Federativa do Brasil: I. Construir uma sociedade livre, justa e solidária; II. garantir o desenvolvimento nacional; III. erradicar a pobreza e a marginalização e reduzir as desigualdades regionais; IV. promover o bem de todos, sem preconceitos de origem, raça, sexo, cor, idade e quaisquer outras formas de discriminação». El contenido del artículo referido demuestra la existencia de desigualdades e injusticias y el compromiso del Estado con su transformación.

En ese sentido, una característica inseparable del Estado Democrático de Derecho es el evidente compromiso con la transformación de la realidad. Tal conclusión es reforzada por la constatación de las frecuentes disposiciones, en el sentido de que «A saúde é direito de todos e dever do Estado»(art. 196); "A educação, direito de todos e dever do Estado e da família» (art. 205). Es cristalino que para realizar tales disposiciones constitucionales el estado debe actuar positivamente.

El Cooperativismo, inserido en el contexto de Estado Democrático de Derecho como instrumento emancipador y democratizador, tuvo tratamiento peculiar por el legislador constitucional. En razón de la función social del cooperativismo, al Acto Cooperativo fue dedicado constitucionalmente tratamiento tributario "adecuado».

En ese sentido, queda evidente que el Estado Democrático de Derecho brasilero, además de evidenciarse como instituto jurídico plenamente compatible con el cooperativismo, le sirve de substrato, delineando normas constitucionales programáticas de incentivo y fomento al movimiento cooperativo. La Constitución de 1988 no se limitó, simplemente, a encerrar el momento de intervencionismo en el cooperativismo, por medio de la prohibición de la intervención estatal, pero evidencio, de forma cristalina, que el Estado debe incentivar y estimular el cooperativismo.

Resumidamente, en la elaboración de una Teoría de la Constitución adecuada a la realidad brasilera, relacionándola al Cooperativismo, deben ser considerados tópicos puntuales por el intérprete que debe: 1) tener en cuenta las vicisitudes del modelo constitucional brasilero y de la protección constitucional dada al Cooperativismo y al acto coope- 
rativo; 2) por medio de esos presupuestos, buscar una comprensión autentica, por medio de la consciencia histórico-efectual, denunciando los prejuicios basados en una tradición liberal que permea el modo-de-ser de los intérpretes; 3 ) percibir el abismo establecido a la realidad social y al texto constitucional, las promesas de la modernidad no cumplidas y las lagunas de la actividad estatal; 4) comprender que para la realización de los objetivos intrínsecos del Estado Democrático de Derecho tal realidad necesita ser transformada; 5) por fin, darse cuenta de que la Constitución, entendida como un instrumento compromisario y dirigente pasa a ser condición de posibilidad para cobrar del Estado una actuación efectiva en favor de la transformación social.

\section{Notas conclusivas}

Mucho se ha hablado a respeto del Acto Cooperativo y a respeto de las teorías que lo han intentado explicar, atribuyéndole alcance y sentido. Lo que se propone es que el alcance del Acto Cooperativo esté relacionado a la actividad finalística, la identificación de la necesidad de su cuadro social, que es suplida por la Cooperativa, en lo que el maestro Walmor Franke entiende como «principio de la identidad».

Es necesario reafirmar categóricamente que el acto cooperativo practicado entre la cooperativa y su socio no solamente es practicado para el cumplimiento del objeto societario y alcance de la finalidad, pero los sujetos de ese acto cooperan entre sí. Por lo tanto, los intereses económicos de esos sujetos (socio y cooperativa) no son opuestos, lo que hace de ese acto cooperativo esencialmente distinto de todo y cualquier acto de mercado.

La propuesta de innovarse, denominando algunos actos de mercado como también de cierto modo, cooperativos, adviene de la conveniencia en enfatizar la unidad y el nexo de las operaciones económicas de la cooperativa, entendidas esas como cadenas de actos que se inician con un acto bilateral cooperativo, tal como reconoce la doctrina e está consagrada en la redacción original del art. 79 de la Ley 5.764/71, pero se proyecta para el ambiente externo, de mercado, para la efectivación de una ventaja patrimonial, receta o facturamiento directo para su socio.

Entonces esa innovación conceptual sirve exactamente para designar que esos actos de mercado, cuando circunscritos a una operación de la cooperativa, en la cual este participando su socio en la doble condición de dueño y usuario, son practicados por cuenta de este. Actuando, en ese sentido, en la prestación de servicios al socio, no existe, 
en esa operación, receta, facturamiento o ventaja patrimonial para la cooperativa.

En resumen, la superación de las controversias y antagonismos relacionados a la interpretación del Acto Cooperativo en el derecho patrio pasa por una interpretación constitucional adecuada, que conciba el Cooperativismo como instrumento adecuado a la ejecución de los objetivos del Estado Democrático de Derecho y vislumbre la Cooperativa el «locus» de convergencia de intereses de los asociados. En ese sentido, a partir de tales presupuestos, resta caracterizado el Acto Cooperativo por la identidad entre los intereses de los asociados y la actuación de la Cooperativa en el mercado. Se trata, en fin, de dar al fenómeno una mirada hermenéutica. Textos no cargan su proprio sentido. La hermenéutica jurídica siempre estuvo preocupada con la tensión entre texto y sentido a ser atribuido. Las insuficiencias de las teorías objetivistas y las arbitrariedades decurrentes de las corrientes subjetivistas son el enfoque principal de la hermenéutica jurídica preocupada con la concretización de los derechos en las democracias contemporáneas. El nivel de autonomía alcanzado por el derecho a partir del segundo pos-guerra no puede venir a ser fragilizado por la «delegación» a favor de las discrecionalidades y/o arbitrariedades del intérprete, o sea, las incertidumbres del lenguaje y/o los casos difíciles (hard cases) no deben depender de concepciones solipsistas. La atribución de sentido a los textos jurídicos debe llevar en cuenta esa superación de las viejas dicotomías que atraviesan el derecho. Dar vida a los textos: esa es la tarea hermenéutica. iConcretizar la constitución: esa es la misión de los juristas!

\section{Referencias}

Bulgarelu, W.: As sociedades cooperativas e sua disciplina jurídica, 2ed., Rio de Janeiro, Renovar, 2000.

Canotilho, J.J.G.: Constituição Dirigente e Vinculação do Legislador: Contributo para a compreensão das normas constitucionais programáticas, Coimbra, Coimbra editora Ltda, 1994.

Gadamer, H.: O problema da consciência histórica. Rio de Janeiro, Editora Fundação Getúlio Vargas, 1998.

Grondin, J.: Introdução à Hermenêutica Filosófica, São Leopoldo, Editora Unisinos, 2004.

HeIdegGer, M.: A Constituição onto-teo-lógica da metafísica, tradução de Ernildo Stein, Pfullingen, Gunther Neske, 1957.

Hesse, K.: Elementos de direito constitucional da República Federal da Alemanha. Porto Alegre: Sergio Antonio Fabris, 1998. 
Hesse, K.: Escritos de derecho constitucional. 2. ed., Madrid, Centro Estud. Constitucionales, 1992.

PIRES, C.: «Heidegger e o ser como história». Revista Portuguesa de Filosofia, Braga, tomo XIX, julho-setembro 1963.

Russel, B.: História do Pensamento Ocidental, Rio de Janeiro, Ediouro, 2004.

SCHNeIDER, O.: Democracia, participação e autonomia cooperativa, São Leopoldo, Editora Unisinos.

SILVA, R.S. da: "Gadamer e a herança Heideggeriana», Revista Portuguesa de Filosofia, 56, 2000.

VATTIMO, G.: Introdução à Heidegger, Lisboa, Edições 70, 1977. 